\title{
Experiences and Illness Perceptions of Patients with Functional Symptoms Admitted to Hyperacute Stroke Wards: A Mixed-Method Study
}

This article was published in the following Dove Press journal: Neuropsychiatric Disease and Treatment

\author{
Nicola O'Connell (1D' \\ Abbeygail Jones $\mathbb{D}^{2}$ \\ Trudie Chalder $\mathbb{D}^{2}$ \\ Anthony S David (iD ${ }^{3}$ \\ 'Department of Public Health and \\ Primary Care, School of Medicine, Trinity \\ College Dublin, Dublin, Ireland; \\ ${ }^{2}$ Department of Psychological Medicine, \\ Institute of Psychiatry, Psychology and \\ Neuroscience, King's College London, \\ London, UK; ${ }^{3} \mathrm{UCL}$ Institute of Mental \\ Health, University College London, \\ London, UK
}

Introduction: A proportion of patients admitted to acute-stroke settings have not had a stroke, but have conditions mimicking a stroke. Approximately $25 \%$ of suspected stroke cases are "stroke mimics" and $2 \%$ are patients with functional symptoms - "functional stroke mimics". This study aimed to explore experiences and illness perceptions of patients with functional symptoms admitted to hyperacute stroke wards.

Methods: This study used mixed methods. Patients with functional stroke symptoms participated in semistructured qualitative interviews immediately after admission to one of two acute-stroke units in London and again 2 months after hospital discharge. Qualitative data were assessed using thematic analysis. The Brief Illness Perception Questionnaire (Brief-IPQ) measured illness perceptions at admission and at 2-month follow-up.

Results: A total of 36 participants completed baseline interviews and 25 completed followup. Six themes emerged: physical symptom experience, emotional and coping responses, symptom causes, hospital experiences, views on the future, and uncertainty after hospital discharge. Mean Brief-IPQ score at admission was 49.3 (SD: 9.9), indicating a moderatehigh level of perceived illness threat. Participants presented with a range of functional symptoms. At baseline, participants were highly concerned about their symptoms, but this had decreased at 2-month follow-up. Two months later, many were confused as to the cause of their admission.

Conclusion: This is the first study to examine functional stroke patients' experiences of acute-stroke admission. At admission, patients expressed confusion regarding their diagnosis, experienced high levels of emotional distress, and were concerned they were perceived as time wasting by stroke clinicians. While most participants experienced symptom recovery, there was a significant subgroup for whom symptoms persisted or worsened. A lack of care guidelines on the management of functional stroke patients may perpetuate functional symptoms.

Keywords: functional stroke symptoms, stroke mimic, unexplained medical symptoms, qualitative research

\section{Introduction}

Stroke services have adapted to advances in diagnostic imaging through the creation of rapid-admission systems that prioritize swift diagnosis and treatment. In 2010, hyperacute stroke units (HASUs) were established in London, replacing existing SUs, leading to improved survival rates and cost-effectiveness. ${ }^{1}$ There are eight HASUs in London, and they are designed to improve the speed of diagnosis and the delivery of stroke treatment through rapid assessment, early
Correspondence: Nicola O'Connell Department of Public Health and Primary Care, Trinity College Dublin, Russell Centre, Tallaght Cross, Dublin 24, Ireland Tel +353 I 8963716

Email noconne@tcd.ie 
treatment, and 24-hour, 7 days/week monitoring and physiological intervention within a high-dependence bed. They are staffed by multidisciplinary teams that include neurologists, neurosurgeons, interventional radiologists, specialist nurses, and therapists. Stroke patients arrive at HASUs via a 999 emergency call via ambulance from home or their GP, arriving at A\&E or as an inpatient having a stroke on a ward at a district general hospital. They are initially assessed in A\&E by an on-call stroke team and receive a computed-tomography brain scan and neurological assessment within 30 minutes and are transferred to the HASU for immediate treatment. The UK's Department of Health launched a stroke-awareness campaign in February 2009, which brought significant reductions in delays to seeking and receiving medical care after major stroke. ${ }^{2}$

A proportion of patients admitted to stroke settings have not had a stroke. Approximately $25 \%$ of suspected stroke cases are "stroke mimics" and $2 \%$ patients with functional symptoms - "functional stroke mimics" (FSMs). ${ }^{3}$ Patients present with neurological patterns resembling stroke superficially, but indicate no specific neurological disorder and have negative findings upon diagnostic testing. FSMs tend to be younger, female, and more frequently present with weakness or numbness compared to other stroke mimics. ${ }^{3}$

How patients experience and interact with the healthcare system can help predict future health outcomes and aid in the design of treatment programs. Previous qualitative research suggests patients with functional symptoms may experience confusion following clinical encounters, and can hold negative attitudes toward clinicians. ${ }^{4}$ Fear of judgment from clinicians is common. ${ }^{5}$ Patients with functional motor disorder have described dissatisfaction with clinical explanations and expressed feelings of abandonment and helplessness. ${ }^{6}$ Such views are of concern, as patients may reject advice and seek other medical input, ${ }^{7}$ potentially leading to iatrogenic harm.

Illness perceptions are an important component of functional disorders, as they help predict illness behavior. ${ }^{8}$ The common-sense model of self-regulation (CSM) is a framework to help understand illness selfmanagement. ${ }^{8,9}$ It states that individuals construct their own understanding of symptoms, which in turn can influence health outcomes. An example of this may be a belief that a symptom is particularly severe, which can result in all-or-nothing behavior. This behavior may in turn lead to worsened disability, which can then reinforce the initial belief that a symptom is severe. Such a cycle can perpetuate and worsen symptoms. Dimensions of the CSM include identity (eg, "I had a stroke"), timeline (eg, "I will live with these symptoms for the rest of my life"), cause (eg, "Psychological stress caused my stroke"), consequences (eg, "I won"t be able to drive"), control (eg, "Nothing I can do will change these symptoms"), and coherence (eg, "My symptoms are confusing"). ${ }^{10}$

The model has been applied in medically unexplained symptom research ${ }^{11}$ and to a limited degree within functional disorders. Functional disorder patients often reject psychological factors as a potential symptom cause, blaming external factors, ${ }^{12}$ although there may be differences according to condition type. For example, patients with functional weakness are less likely to endorse psychological formulations than non-epileptic seizure patients. ${ }^{13}$ In neurology-outpatient clinics, nonattribution of unexplained symptoms to psychological factors was predictive of poorer outcomes. ${ }^{14}$ Conversely, a meta-analysis of 23 studies found the perception of medically unexplained symptoms as a psychological cause was related to negative outcomes. ${ }^{11}$ Less is known about the other aspects of symptom-perception dimensions.

Explorations of functional patients' health-care experiences and illness perceptions often come from primarycare settings or outpatient settings. No study has explored functional stroke patients' experiences or illness perceptions within acute settings. Their experiences likely differ from other functional groups, due to stroke medicine's emphasis on fast diagnosis and treatment, the contextual effect of observing acutely unwell stroke patients, and the effect of the acute environment on staff members' working practices. There is no evidence on the short- to mediumterm consequences of stroke admission on functional patients' symptom perceptions. Improving understanding of illness perceptions and how these change over time can inform efforts to improve treatments.

The aim of this study was to examine health-care experiences and illness perceptions of patients with functional stroke symptoms admitted to HASUs and how these changed over time using qualitative interviews and the Brief Illness Perception Questionnaire (BIPQ). Qualitative research is particularly useful in understanding complex aspects of subjective experience. ${ }^{15}$ We utilized the BIPQ to quantify illness perceptions within the CSM framework and to achieve methodological triangulation. By better understanding patients' own perspectives, we hope to 
inform the development of future treatments and care pathways for these patients.

\section{Methods}

\section{Study Design and Setting}

This study took place in HASUs in King's College Hospital and Princess Royal University in south London between January and October 2016. Additional interviews took place between January and May 2019, and were conducted by NOC and AJ. Additional interviews were completed to update data collection and achieve data saturation. We used semistructured interviews to explore the attitudes, experiences, and illness perceptions of FSM patients. Participants were interviewed at their bedside shortly after admission (baseline) and reinterviewed 2 months after discharge via Skype (2-month follow-up). We used the consolidated criteria for reporting qualitative research (COREQ) to guide the writing of this study (Supplementary Material A). Ethical approval was granted by the Queen Square Research Ethics Committee (REC) (15/LO/1914) on January 6, 2016 and for the 2019 interviews on December 8, 2018 by the Riverside REC (18/LO/ 1878).

\section{Sampling and Recruitment Procedure}

We employed total-population sampling. Participants were included if they were aged 18 years or over, able to communicate in English, and there was no stroke etiology but a functional or psychological explanation for symptoms. Participants were included if they had suspected stroke, had arrived at the hospitals' A\&E (via selfreferral, ambulance, or GP referral), and had subsequently been admitted to the HASU. We also included patients with stroke who experienced co-morbid functional neurological symptoms. Participants were not robustly clinically established functional neurological disorder patients, but rather our sample were patients experiencing "unexplained stroke symptoms" or stroke patients with comorbid functional symptoms. We excluded stroke patients with anxiety or depression only but no functional symptoms, as the focus of this study was functional stroke alone.

The researchers attended HASU-handover meetings throughout the study period. Patients fitting the inclusion criteria were identified by the medical team at these meetings and referred to a study researcher. In all cases, participants had received a full neurological assessment in radiological imaging, commonly brain computed tomography and often magnetic resonance imaging by a stroke physician with at least a 5-year postgraduate qualification. In all cases, the stroke clinician referring the patient to the research team had made a clinical judgment that the patient's symptoms were either entirely or partially explained as a functional diagnosis based on their neurological assessment and/or radiological findings. A stroke clinician asked permission from the patient for the researcher to discuss the study, who then explained that the study's purpose was to develop understanding of functional stroke admissions. The researcher provided a studyinformation sheet and consent form. Interviews were recorded using a Dictaphone. Follow-up interviews were conducted via Skype and recorded.

Most commonly, baseline interviews took place after a clinician had seen the patient and radiological tests had been completed. Due to the high turnover on the ward and high demand for beds, functional patients were often discharged quickly after a nonstroke diagnosis. To ensure an interview took place, in a small number of cases it was necessary for researchers to interview patients where a stroke clinician strongly suspected functional symptoms but radiological results were pending. In only one case did the magnetic resonance imaging scan reveal a stroke, contradicting the neurological assessment. This participant's data were not included in the study.

\section{Data Collection}

Participants were interviewed at the bedside. The interviewer had no relationship to the participant prior to the study. Interviews were semistructured and informed by a topic guide (Supplementary Material B). The same topic guide was followed for both sets of interviews, but follow-up interviews explored experiences since discharge, rather than experiences on the ward. The topic guide explored ${ }^{1}$ admission experiences, ${ }^{2}$ history and experience of symptoms, ${ }^{3}$ illness beliefs and attitudes, and $^{4}$ views on the future. All interviews were transcribed verbatim by NOC and AJ.

\section{Data Analysis}

Data were analyzed using Braun and Clarke's thematic analysis approach. ${ }^{16}$ This involved familiarization through transcription, reading and rereading data, and the generation of initial codes. NOC and AJ independently coded interviews and discussed the emergence of themes. Themes were reviewed, defined, and refined by both 
authors (see Supplementary Material C for coding framework). Analyses were conducted using NVivo software. Participants' names are not presented in this text. All names in the text are pseudonyms. NOC and AJ have backgrounds in psychological research. NOC kept a research diary to interpret and reflect on interviews. The role of potential researcher or observational bias was discussed by the research team (NOC, AJ, ASD, and TC) to aid the qualitative analysis process.

The BIPQ was developed by Broadbent et $\mathrm{al}^{17}$ and consists of eight items measured on a continuous scale from one to ten (less threatening to highly threatening view of symptoms). Each item assesses a dimension of illness perception. Total scores range from 0 to 80 , with higher scores indicating more threatening perceptions. The questionnaire has good psychometric properties. ${ }^{18}$ Repeated-measure Wilcoxon signed-ranks test compared the mean score of items at baseline with follow-up. We analyzed scores using SPSS version 22.

\section{Results}

We interviewed 36 participants (24 females, 66.7\%) at baseline and 26 of those again at 2-month follow-up (17 females, $68 \%$ ). No patient refused to take part, and those who were not followed up at 2 months were uncontactable, rather than refusing participation. Mean age was $51 \pm 15.3$ years. The most common ethnicity was white British (22, $61.1 \%)$. Sixteen (44.4\%) were employed and eleven (30.6\%) unemployed or on medical leave at admission. The ten participants who did not take part in the follow-up interview had a mean age of $54 \pm 14.4$ years, five $(50 \%)$ were white British, and five unemployed (50\%). Table 1 displays all participants' symptom profiles at admission. Interviews took 7-65 minutes. Mean number of days between baseline and follow-up was $70 \pm 16.7$. A total of 28 participants completed the BIPQ at baseline, and 23 completed a follow-up questionnaire. There were no differences in age or sex of participants completing one survey compared to those completing both baseline and follow-up.

\section{Brief Illness Perception Questionnaire Results}

Mean total BIPQ score at baseline was $50.0 \pm 10.1$, and at 2-month follow-up it fell to $39 \pm 20.1$.
Table I Clinical Characteristics at HASU Admission

\begin{tabular}{|c|c|}
\hline Symptoms & Age, Years \\
\hline Left-sided facial weakness, left-arm weakness & Not known \\
\hline Expressive dysphasia & 23 \\
\hline Facial numbness & 29 \\
\hline Severe headache and dysarthria & 20 \\
\hline $\begin{array}{l}\text { Frontal bilateral headache, right-sided pain, and mild } \\
\text { disequilibrium }\end{array}$ & 65 \\
\hline $\begin{array}{l}\text { Left-sided weakness and dysphasia, history of functional } \\
\text { seizures }\end{array}$ & 56 \\
\hline $\begin{array}{l}\text { Left-sided weakness, left visual disturbance, and } \\
\text { headache }\end{array}$ & 43 \\
\hline Light-headed, history of stroke & 67 \\
\hline Left-sided pain & Not known \\
\hline Rotatory vertigo, chronic fatigue, and depression & 62 \\
\hline Left-sided facial droop and slurred speech & 53 \\
\hline Dysphasia and headache & 33 \\
\hline Left-hand numbness and expressive dysphasia & 64 \\
\hline $\begin{array}{l}\text { Right-sided weakness, headache, photophobia, history } \\
\text { of bipolar disorder }\end{array}$ & Not known \\
\hline $\begin{array}{l}\text { Several episodes of loss of consciousness with left-sided } \\
\text { weakness }\end{array}$ & 21 \\
\hline $\begin{array}{l}\text { Left-sided weakness, history of previous stroke with } \\
\text { functional symptoms }\end{array}$ & 88 \\
\hline $\begin{array}{l}\text { Reduced finger movements in both hands and muddled } \\
\text { speech }\end{array}$ & Not known \\
\hline Sudden-onset speech disturbance, history of anxiety & 53 \\
\hline Left-sided weakness and facial droop & 31 \\
\hline $\begin{array}{l}\text { Left-sided weakness and numbness, history of stroke } \\
\text { with functional symptoms }\end{array}$ & 59 \\
\hline $\begin{array}{l}\text { Migraine, left-face and -arm weakness, history of stroke } \\
\text { and CFS }\end{array}$ & 38 \\
\hline Dysarthria, dysphasia, dizziness, and posterior headache & 52 \\
\hline $\begin{array}{l}\text { Left-sided weakness and frontal lobe headache, } \\
\text { confirmed stroke with functional symptoms }\end{array}$ & 53 \\
\hline Left-sided weakness, history of depression & 50 \\
\hline $\begin{array}{l}\text { Hyperventilation and shaking of upper and lower limbs } \\
\text { following local dental anesthetic }\end{array}$ & 58 \\
\hline Right-sided weakness, history of PTSD & 55 \\
\hline Left-face droop and speech slurring & 51 \\
\hline $\begin{array}{l}\text { Left-sided headache, dizziness, diplopia, history of } \\
\text { depression and fibromyalgia }\end{array}$ & 49 \\
\hline Left-face weakness, dysarthria, and left-face paresthesia & 49 \\
\hline $\begin{array}{l}\text { Left-face droop, left-arm and -face paresthesia, } \\
\text { confirmed stroke with functional symptoms }\end{array}$ & 51 \\
\hline $\begin{array}{l}\text { Headache, collapse, dysarthria, blurry vision, and left- } \\
\text { sided weakness }\end{array}$ & 64 \\
\hline $\begin{array}{l}\text { Confusion, left-sided weakness, slurred speech, } \\
\text { swallowing difficulty, horizontal and vertical diplopia }\end{array}$ & 56 \\
\hline $\begin{array}{l}\text { Slurred speech, lateral-gaze diplopia, nystagmus (all } \\
\text { directions), upper-limb ataxia }\end{array}$ & 51 \\
\hline
\end{tabular}

(Continued) 
Table I (Continued).

\begin{tabular}{|l|l|}
\hline Symptoms & Age, Years \\
\hline $\begin{array}{l}\text { Pain and weakness on right side, bilateral leg weakness, } \\
\text { collapse, dizziness, migrainous headache, difficulty } \\
\text { swallowing }\end{array}$ & 51 \\
$\begin{array}{l}\text { Right-sided weakness, nausea, confusion, speech slow, } \\
\text { ataxic, disoriented }\end{array}$ & 75 \\
\hline
\end{tabular}

Figure 1 displays a paired-scatter chart of individual mean scores at baseline and follow-up, and Table 3 displays two vignettes describing a patient whose symptoms got worse and a patient whose symptoms improved. We chose these vignettes to highlight the variability in recovery and to illustrate an example of positive recovery and a case where symptoms worsened. There were considerable missing data for total mean scores, as many participants did not complete all follow-up questionnaire items, meaning individual total scores could not be calculated. Three participants completed all items at both baseline and follow-up.

Table 2 presents BIPQ component scores. At baseline, "concern about symptoms" was most highly scored (perceived as threatening), and at 2-month follow-up this was scored as moderate. At baseline, the lowest-rated component was "treatment control", indicating participants believed treatment would be helpful. Repeated-measure analyses were conducted to assess changes in mean scores over time. Mean perceived consequences $(Z=-3.4, p=0.001)$, identity $(Z=-2.1, p=0.04)$, concern $(Z=-2.7, p=0.01)$, and emotional response $(Z=-2.0$, $p=0.05$ ) decreased significantly.

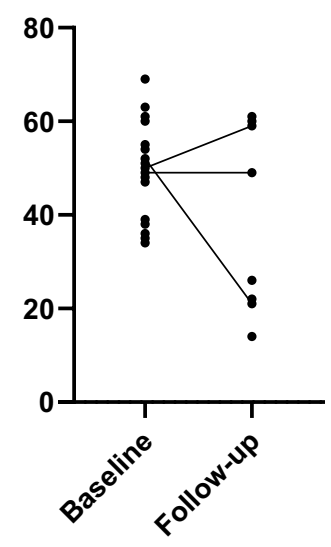

Figure I Changes in individual total B-IPQ scores between baseline and 2-month follow-up. Lower scores indicate symptoms perceived as less threatening.

\section{Qualitative Results}

Six themes emerged from qualitative data analysis: ${ }^{1}$ physical symptom experiences, ${ }^{2}$ emotional and coping responses, ${ }^{3}$ symptom causes, ${ }^{4}$ hospital experiences, ${ }^{5}$ views on the future, and $^{6}$ uncertainty after hospital discharge.

\section{Physical Symptom Experiences}

Symptom onset was commonly marked by feeling faint, disorientated, dizzy, or losing balance. The most common symptoms included weakness, numbness, pins and needles, nausea, headache, migraine, pain, visual disturbance, memory loss, loss of speech, disturbed speech, fatigue, and facial droop. Symptoms were rarely discrete, with multiple and varied symptoms often developing between initial onset and admission.

It was this sort of thorough sense of unreality . . . everything looked out of, slightly out of kilter, slightly swimmy, I could feel the numbness here [gestures to right arm]. I caught the reflection in the mirror, I saw that my eyes had dropped - pins and needles. (Linda, aged 51 years)

Participants described an array of chronic preexisting physical and mental health comorbidities, including anxiety, depression, nonepileptic seizures, irritable bowel syndrome, fibromyalgia, hypertension, diabetes, angina, stroke, migraine, back pain, slipped disks, and history of breast cancer, prostate cancer, osteoarthritis, transient ischemic attacks, and hernias. Several reported a family history of stroke.

\section{Emotional and Coping Responses}

For many, symptom onset and hospital admission were highly upsetting. Participants described feeling shocked, numb, panicked, depressed, scared, or frightened. Many were concerned the symptoms represented something serious.

I panicked and I broke down because I did not know what was happening ... my line manager looked at me, asked if I was okay. I go, “I don't know what's happening to me. I can't use my hands". (Andrew, age unknown)

Participants described varied coping responses. Several felt their physical symptoms were something they would have to endure indefinitely and symptoms were beyond their control. Others described the need to display resilience for family members.

I do feel little bit [low] but I cannot let the wife see that because I have got to be strong for her. (Noel, aged 56 years) 
Table 2 Brief Illness Perception Questionnaire-Component Results Measured at Baseline and 2-Month Follow-up

\begin{tabular}{|c|c|c|c|c|c|c|}
\hline & Baseline, edian (IQR) & Follow-up, edian (IQR) & Wilcoxon signed-rank Z & $p$ & $\delta$ & Change \\
\hline Consequences & $8(6-10)$ & $2.5(0-6.25)$ & -3.4 & 0.001 & 1.25 & High to low \\
\hline Timeline $^{a}$ & $5.83(2.9)$ & $5.2(4.3)$ & 0.42 & 0.68 & 0.18 & Moderate to none \\
\hline Personal control & $10(4-10)$ & $5(2-10)$ & -0.49 & 0.62 & 0.21 & High to moderate \\
\hline Treatment control & $2.5(0.5-5.0)$ & I $(0-5)$ & -0.85 & 0.39 & 0.22 & Low to none \\
\hline Identity & $5(4-7)$ & $3(0-6)$ & -2.1 & 0.04 & 0.44 & Moderate to low \\
\hline Concern & $8(6.25-10)$ & $5(0-10)$ & -2.7 & 0.01 & 0.84 & High to moderate \\
\hline Understanding & $5(2-9)$ & $5(0-10)$ & -0.47 & 0.64 & 0.07 & Moderate to none \\
\hline Emotional response & $8(5-10)$ & $5(2-9)$ & -2 & 0.05 & 0.69 & High to moderate \\
\hline
\end{tabular}

Notes: ${ }^{a}$ Normally distributed data, so $t$-test used. $p$-values in bold indicate statistically significant results Cohen's $\delta$ : very small, 0.01 ; small, $0.2 ;$ medium, 0.5 ; large, 0.8 ; very large, I.2; huge, 2.

\section{Symptom Causes}

A significant proportion of participants believed they had had a stroke when first interviewed, although their understanding of what occurred was unspecific. They described a range of possible stroke triggers, such as unhealthy behavior, anxiety, stress, tiredness, heat exhaustion, grief, panic, a virus, medication side effects, genetics, or comorbidities like osteoarthritis and cancer. While many endorsed psychological stress as a symptom cause, this was ambiguous, as they believed stress had triggered a stroke. In cases where participants did not believe they had had a stroke, they expressed confusion, rather than any definitive cause.

I am assuming it could just be all the stress building up and then the stroke. (Emily, aged 33 years)

Mentally, things like strokes happen if you are worried too much - too much pressure, you know. (Marie, aged 64 years)

I try to understand it, but at this moment in time I am just so confused. (Kirsten, aged 21 years)

\section{Hospital Experiences}

Participants described receiving fast responses from ambulances, swift admissions, rapid diagnostic testing, and intense clinical observation with hourly checks. Many were dissatisfied with the explanation they received from doctors on symptom cause, and some felt judged or invalidated by staff.

They said that evening, "Well, we think you've had a stroke" .. . The next day, they came back to me and started talking about me weirdly, without even saying hello first. . . I do not know what they thought. That I was young, maybe I was on drugs . . . They were not taking it seriously ... They just kind of said they do not think it's a stroke - it could have been a small stroke, but they do not think that it is ... And that was a little bit worrying. (Michael, aged 23 years)

I was very angry at first, because it's as if you are putting it on and wasting people's time, but I am not that sort of person. I do not like hospitals. (Noel, aged 56 years)

\section{Views on the Future}

Participants expressed anxiety that symptoms would reoccur, although there were differences in how participants planned to engage in future work and leisure activities. Some saw their hospital admission as an opportunity to adapt their lifestyle, others decided they required rest, and some were fearful that activity might bring a reoccurrence of symptoms.

If I change my lifestyle completely, I think that will help . . . I think in terms of eating and exercise. (Lucy, aged 53 years)

I have got to slow down . . . like my brain goes fast, but my body does not move with it . . I have just got to slow down, not get so stressed out and whatever ... like it could happen again ... so I am like worried now, in case it happens again. (Sandra, aged 62 years)

\section{Uncertainty after Hospital Discharge}

At 2 months postdischarge, ten participants (40\%) reported no symptom improvement, four (16\%) partial 
Table 3 Vignettes of Deterioration and Improvement

\begin{tabular}{|c|c|c|}
\hline & A. Vignette Describing Deterioration & B. Vignette Describing Improvement \\
\hline Admission & $\begin{array}{l}\text { White British male full-time volunteer admitted following } \\
\text { several bouts of loss of consciousness with left-sided weakness. }\end{array}$ & $\begin{array}{l}\text { White British female admitted with reduced finger movements } \\
\text { and muddled speech, with symptoms lasting } 30 \text { minutes before } \\
\text { resolving. Symptoms reccurred later that day and resolved. No } \\
\text { neurological deficit. MRI showed no evidence of ischemia. }\end{array}$ \\
\hline Risk factors & $\begin{array}{l}\text { Childhood asthma, diabetes since age } 15 \text { years, and an } \\
\text { asymptomatic congenital cerebral cyst. No acute infarction, and } \\
\text { intracranial appearances were normal. }\end{array}$ & Familial hypercholesterolemia and arthritis. \\
\hline $\begin{array}{l}\text { Symptom } \\
\text { onset }\end{array}$ & Traveling for holidays, felt unwell, and had lost consciousness. & $\begin{array}{l}\text { Cramping and pressure in both hands began during work } \\
\text { presentation and following a busy work period. Colleague } \\
\text { noticed patient using words out of context. }\end{array}$ \\
\hline $\begin{array}{l}\text { Family } \\
\text { history }\end{array}$ & $\begin{array}{l}\text { Difficult relationship with family, father had recent major } \\
\text { surgery. Mother a full-time carer. }\end{array}$ & $\begin{array}{l}\text { Supportive husband and family who stayed with patient } \\
\text { throughout admission. }\end{array}$ \\
\hline $\begin{array}{l}\text { Experience } \\
\text { on stroke } \\
\text { ward }\end{array}$ & $\begin{array}{l}\text { Did not believe physical functioning would return to normal and } \\
\text { expressed belief that symptoms would significantly change his } \\
\text { life. }\end{array}$ & $\begin{array}{l}\text { Stroke team explained she had not had a stroke and symptoms } \\
\text { likely stress- or exhaustion-induced. Recommendation she see } \\
\text { GP for follow-up to assess symptom in hand. Expressed relief } \\
\text { symptoms were not a stroke. }\end{array}$ \\
\hline $\begin{array}{l}\text { Two-month } \\
\text { follow-up }\end{array}$ & $\begin{array}{l}\text { Patient was referred to psychiatric inpatient ward and received } \\
\text { physiotherapy for his leg. Later transferred to a psychiatric } \\
\text { inpatient ward closer to home and subsequently discharged to } \\
\text { supported accommodation. Continued deterioration in family } \\
\text { relationships, reduced function in left leg, and had developed fits/ } \\
\text { seizures. At follow-up, the patient had received an appointment } \\
\text { for with neurology to investigate the seizures further. }\end{array}$ & $\begin{array}{l}\text { Continued to experience hand cramping with GP monitoring } \\
\text { symptoms. She had taken up running to develop fitness and lose } \\
\text { weight. Continued to be busy in work, but employers agreed to } \\
\text { reduce work-related traveling. She had also begun to develop } \\
\text { strategies to help reduce work-related anxiety. }\end{array}$ \\
\hline
\end{tabular}

Notes: Section A describes a patient whose BIPQ scores had deteriorated at 2-month follow-up following stroke admission. Section B describes a patient who had recovered at 2-month follow-up. Some details have been changed to preserve anonymity.

improvement, and eleven (44\%) complete resolution. For patients with symptom improvements, some reported general health benefits as a result of increased physical activity. For those with persistent symptoms, some had experienced increased intensity or new symptoms had emerged.

I get a really bad headache, I feel sick, I start struggling to breathe. Whether that's stress or anxiety, I do not know, and then I feel really dizzy . . . that lasts for about 10 minutes and I go into seizure. All I know is that it's pretty violent. (Kirsten, aged 21 years)

At follow-up, most participants had been told they had not had a stroke. Some held psychological formulations describing stress, exhaustion, and nerves, while others remained confused. This uncertainty was a source of continued worry for some participants, while others had learned to accept it.

They suspected that I had ministroke, but later, when they discharged me, that's why I am still confused. They said, "No, you have not had a ministroke" ... it seemed to me that they could not give me the right information and I was discharged without being, without knowing exactly what happened. (Marie, aged 64 years)

Occasionally, I get a little bit anxious about it, but not really, not to the point where it stops me living my life. Brains are complex things, that's the only thing I'd say. (Michael, aged 23 years)

\section{Discussion}

This study examined the health-care experiences and illness representations of functional stroke patients and how these had changed at 2-month follow-up. Our qualitative findings suggest patients experienced a wide variety of symptoms prior to admission. The variability in length of interviews reflects this heterogeneous sample and symptomatology, with some participants more eager or able to engage with the interview and questionnaire than others. Time spent in hospital was often upsetting and confusing. On the HASU, many participants accepted psychological 
factors as potential stroke triggers, but maintained a biological understanding of symptom etiology. Two months later, most understood they had not experienced a stroke, but were confused regarding the cause. This uncertainty was a source of anxiety for some, while others accepted the lack of information and reported recovery.

Our BIPQ findings echoed the qualitative findings and reflected the intense emotional response and high degree of concern described. At admission, patients believed there would be severe future consequences, did not believe they had control over symptoms, and were highly distressed. The mean emotional response score was higher than scores reported in lung cancer and melanoma ${ }^{19}$ and heart-failure patients. $^{20}$ The consequence score was similar to mean scores reported in breast cancer, ${ }^{21}$ lung cancer, ${ }^{22}$ and patients with depression in advanced palliative care. ${ }^{23}$

While the total mean scores indicated that the perception of symptoms as threatening had improved at 2-month follow-up, the graphical display of individual scores over time indicates that a subgroup of participants' perceptions worsened. This group would likely benefit from more targeted intervention within the stroke ward prior to discharge or referral to other interventions. ${ }^{24}$ The vignettes suggest family support, employment, and belief in symptom control are protective factors in recovery.

The sense of not being taken seriously or concern that others believe you are faking symptoms is common in patients with medically unexplained symptoms, $5,25--27$ and was observed in this study. This finding is of concern, as concordant beliefs between patient and clinician lead to greater satisfaction and better health outcomes. ${ }^{28}$ Feeling misunderstood or undeserving of clinical care may encourage resistance to future health-care professionals or health-care advice, with subsequent delays in diagnosis, increased referrals, and seeking of alternative treatments outside the medical mainstream. ${ }^{6}$ Further, as in the case of Kirsten, it may lead to a worsening of the person's condition with the accretion of new symptoms (eg, the onset of seizures). Functional patients could also benefit from the inclusion of their caregivers in follow-up appointments to help carers better understand functional symptoms and provide training or information on how best to support the patient outside the hospital.

Participants' understanding of symptom causes was similar to qualitative findings from functional motordisorder patients who commonly rejected psychological explanations. ${ }^{6}$ Stone et $\mathrm{al}^{29}$ found patients with functional weakness frequently attributed symptoms to "undiscovered physical causes" or "damage to the nervous system". Patients in this study were happy to endorse psychological factors as a possible organic stroke trigger, but at least at baseline most believed they had suffered an organic stroke. Two months after discharge, many remained confused about symptom origins, a finding similar to patients experiencing functional seizures. ${ }^{30}$ Increased anxiety at 2 months may be partially mediated by lower acceptance of diagnostic uncertainty.

Patients' illness representations are influenced by encounters with their doctors. The confusion about cause is reflective of the lack of clarity provided in the early stages of admission. This is partly a practical requirement, as staff await scan results before giving definitive diagnoses and patients with functional stroke are more likely to receive brain imaging as doctors seek to mitigate risks of falsenegative diagnoses. ${ }^{3}$ Ambiguous bedside consultations ${ }^{31}$ coupled with the speed of admission, urgency of diagnostic screening, and sharing a ward with acutely unwell stroke sufferers may compound initial confusion and lead to purely biological symptom perceptions.

That etiological confusion continues at 2-month follow-up suggests a clinical opportunity has been missed. While there is likely a variety of potential symptom causes, patients with functional symptoms who reject psychological factors entirely may be less likely to address psychological components in recovery, which could compound their functional symptoms. We did not examine participants' hospital records, but instead focused on selfreported experiences, both on the ward and after discharge from the SU. At the 2-month follow-up interview, most participants described receiving an outpatient follow-up appointment with a stroke consultant or doctor. One participant describing receiving acute psychiatric inpatient care, but none described receiving outpatient counseling for their symptoms, either by the hospital, GP, or selfreferral. There is a need for candid neurological consultation prior to discharge (either by the stroke doctor or the hospital liaison psychiatrist or neuropsychologist if available), greater information provision at stroke follow-up, and increased referral or signposting to other services. It is important stroke clinicians engage with the many guidelines on how to address and manage functional symptoms. $^{24,32,33}$

This study has a number of limitations. These findings represent results from one city with a specific hyperacute stroke model, although versions of acute SUs now exist in 
most major cities in the world. ${ }^{3}$ This qualitative research was designed to understand and explore patients' experiences and phenomenological accounts of their admission, rather than to elucidate the potential sociodemographic factors that influenced outcomes. This would be a fruitful subject for future research. We identified a relatively small number of participants. This may have been due to the sampling procedure, which relied on doctors to identify and approach participants initially. This study was not an incidence study, however, so conclusions on admission rates cannot be drawn. We included a heterogeneous patient sample, as well as patients who had experienced a stroke but presented with comorbid functional symptoms $(n=2)$ and patients with functional symptoms but who had a history of stroke $(n=4)$. While their inclusion has made our sample more diverse, it is a more accurate reflection of the diversity and complexity of functional symptoms and functional symptomatology on stroke wards generally. The definition of functional comorbidity is relatively unspecific, and while it will vary between neurology and stroke consultants, it is commonly deployed, increasing the generalizability of our findings. By the same token, our results are less generalizable to specific diagnostic groups, eg, well-defined functional neurological disorders. The heterogeneity of symptoms has implications for the interpretation of BIPQ results. A larger sample would have allowed for symptom type to be accounted for in our analysis. We did not include stroke patients with anxiety or depression who did not have functional symptoms. While stroke and anxiety or depression is a well-recognized phenomenon, these patients likely have a separate etiology and clinical profile compared to functional stroke presentations. We did not have access to participants' hospital records, so could not account for treatment interventions or possible effect on BIPQ scores. One participant with no stroke described receiving thrombolysis at admission, finding the treatment beneficial. Most participants described receiving diagnostic tests, however, as well as some prescriptions, such as blood-pressure medication like warfarin, but no interventional treatments.

This is the first qualitative study of unexplained stroke mimics. Interviews occurred over two time periods, capturing change over time, a rare but powerful qualitative design. Our sample size was large, allowing us to reach data saturation. By conducting interviews at the HASU, we captured a degree of immediacy in experiences. Functional symptoms are a persistent presentation to stroke settings. Stroke care has developed a highly interventionist service model since the reorganization of services. This, coupled with public-awareness campaigns, has led to significant improvements in stroke mortality. The elements of the improved model that have proved effective for stroke patients have most likely led to increased functional stroke presentations. As these patients seek and often fail to find reassurance and diagnostic clarity from their clinicians, these symptoms may become more entrenched and more difficult to treat with time. With no clinical guidelines and the potential for great iatrogenic harm, a clear care pathway is necessary to improve functional patients' outcomes and to ensure the delivery of high-quality care to this long-neglected patient group.

\section{Ethics}

We confirm this study was conducted in accordance with the Declaration of Helsinki. All participants provided informed consent, including publication of their responses and the case details in Figure 1. All names given in this document are pseudonyms.

\section{Acknowledgments}

The authors would like to thank the clinicians at the HASUs at King's College Hospital and the Princess Royal University Hospital for facilitating patient recruitment and the participants who took part in this study.

\section{Funding}

NOC received $\mathrm{PhD}$ funding from the National Institute for Health Research (NIHR) Biomedical Research Centre (BRC) at South London and Maudsley NHS Foundation Trust. Part of this research was supported by the King's Health Partners Research and Development Challenge Fund (grant RE13522) "Functional Stroke Mimics: consecutive survey and intervention development" (Chalder, T (co-PI) and David, A (co-PI). The funding bodies had no role in the design, analysis, or writing of this paper.

\section{Disclosure}

Professor Trudie Chalder reports grants from the King's Challenge Fund (£78,468; April 1, 2018-March 31, 2019). The authors report no proprietary or commercial interest in any product mentioned or concept discussed in this article. Some of the results of this study were reported in NOC's $\mathrm{PhD}$ thesis; however, this has been substantially reworded and contains new data that did not appear in the original 
thesis. The authors report no other conflicts of interest in this work.

\section{References}

1. Hunter RM, Davie C, Rudd A, et al. Impact on clinical and cost outcomes of a centralized approach to acute stroke care in london: a comparative effectiveness before and after model. PLoS One. 2013;8(8):e70420. doi:10.1371/journal.pone.0070420

2. Wolters FJ, Paul NLM, Li L, Rothwell PM. Sustained impact of uk fast-test public education on response to stroke: a population-based time-series study. Int J Stroke. 2015;10(7):1108-1114. doi:10.1111/ ijs. 12484

3. Jones AT, O'Connell NK, David AS. Epidemiology of functional stroke mimic patients: a systematic review and meta-analysis. Eur $J$ Neurol. 2020;27(1):18-26. doi:10.1111/ene.14069

4. Wyatt C, Laraway A, Weatherhead S. The experience of adjusting to a diagnosis of non-epileptic attack disorder (NEAD) and the subsequent process of psychological therapy. Seizure. 2014;23(9):799-807. doi:10.1016/j.seizure.2014.06.012

5. Nettleton S, Watt I, O'Malley L, Duffey P. Understanding the narratives of people who live with medically unexplained illness. Patient Edu Counseling. 2005;56(2):205-210. doi:10.1016/j.pec.2004.02.010

6. Nielsen G, Buszewicz M, Edwards MJ, Stevenson F. A qualitative study of the experiences and perceptions of patients with functional motor disorder. Disability Rehab. 2019;1-6. doi:10.1080/ 09638288.2018 .1550685

7. Hunt LM, Jordan B, Irwin S, Browner $\mathrm{CH}$. Compliance and the patient's perspective: controlling symptoms in everyday life. Culture, Med Psychiatry. 1989;13(3):315-334. doi:10.1007/BF000 54341

8. Hagger MS, Orbell S. A meta-analytic review of the common-sense model of illness representations. Psychol Health. 2003;18 (2):141-184. doi:10.1080/088704403100081321

9. Leventhal H, Diefenbach M, Leventhal EA. Illness cognition: using common sense to understand treatment adherence and affect cognition interactions. Cognitive Ther Res. 1992;16(2):143-163. doi:10.1007/BF01173486

10. Leventhal H, Leventhal EA, Breland JY. Cognitive science speaks to the "common-sense" of chronic illness management. Ann Behav Med. 2011;41(2):152-163. doi:10.1007/s12160-010-9246-9

11. McAndrew LM, Crede M, Maestro K, Slotkin S, Kimber J, Phillips LA. Using the common-sense model to understand health outcomes for medically unexplained symptoms: a meta-analysis. Health Psychol Rev. 2019;13(4):427-446. doi:10.1080/17437199. 2018.1521730

12. Stone J, Binzer M, Sharpe M. Illness beliefs and locus of control: A comparison of patients with pseudoseizures and epilepsy. J Psychosomatic Res. 2004;57(6):541-547. doi:10.1016/j.jpsychores. 2004.03.013

13. Ludwig L, Whitehead K, Sharpe M, Reuber M, Stone J. Differences in illness perceptions between patients with non-epileptic seizures and functional limb weakness. J Psychosomatic Res. 2015;79 (3):246-249. doi:10.1016/j.jpsychores.2015.05.010

14. Sharpe M, Stone J, Hibberd C, et al. Neurology out-patients with symptoms unexplained by disease: illness beliefs and financial benefits predict 1-year outcome. Psychol Med. 2010;40(4):689-698. doi: $10.1017 /$ S0033291709990717

15. Fossey E, Harvey C, McDermott F, Davidson L. Understanding and evaluating qualitative research. Aust New Zealand J Psychiatry. 2002;36(6):717-732. doi:10.1046/j.1440-1614.2002.01100.x

16. Braun V, Clarke V. Using thematic analysis in psychology. Qual Res Psychol. 2006;3(2):77-101. doi:10.1191/1478088706qp063oa
17. Broadbent E, Ellis CJ, Thomas J, Gamble G, Petrie KJ. Further development of an illness perception intervention for myocardial infarction patients: a randomized controlled trial. J Psychosomatic Res. 2009;67(1):17-23. doi:10.1016/j.jpsychores.2008.12.001

18. Broadbent E, Wilkes C, Koschwanez H, Weinman J, Norton S, Petrie KJ. A systematic review and meta-analysis of the brief illness perception questionnaire. Psychol Health. 2015;30(11):1361-1385. doi:10.1080/08870446.2015.1070851

19. Hoogerwerf MA, Ninaber MK, Willems LNA, Kaptein AA. "Feelings are facts": illness perceptions in patients with lung cancer. Respir Med. 2012;106(8):1170-1176. doi:10.1016/j.rmed.2012.04. 006

20. Lerdal A, Hofoss D, Gay CL, Fagermoen MS. Perception of illness among patients with heart failure is related to their general health independently of their mood and functional capacity. $J$ Patient Rep Outcomes. 2019;3(1):55. doi:10.1186/s41687-019-0142-1

21. Kaptein AA, Yamaoka K, Snoei L, et al. Illness perceptions and quality of life in Japanese and Dutch women with breast cancer. J Psychosoc Oncol. 2013;31(1):83-102. doi:10.1080/07347332. 2012.741092

22. Kaptein AA, Yamaoka K, Snoei L, et al. Illness perceptions and quality of life in Japanese and Dutch patients with non-small-cell lung cancer. Lung Cancer. 2011;72(3):384-390. doi:10.1016/j. lungcan.2010.09.010

23. Price A, Goodwin L, Rayner L, et al. Illness perceptions, adjustment to illness, and depression in a palliative care population. $J$ Pain Symptom Manage. 2012;43(5):819-832. doi:10.1016/j.jpainsymman. 2011.05.013

24. Jones A, O'Connell N, David AS, Chalder T. Functional stroke symptoms: a narrative review and conceptual model. J Neuropsychiatry Clin Neurosci. 2019;32(1):14-23. doi:10.1176/ appi.neuropsych.19030075

25. Peters S, Rogers A, Salmon P, et al. What do patients choose to tell their doctors? Qualitative analysis of potential barriers to reattributing medically unexplained symptoms. J General Int Med. 2009;24:443. doi:10.1007/s11606-008-0872-x

26. Salmon P, Peters S, Stanley I. Patients' perceptions of medical explanations for somatisation disorders: qualitative analysis. $B M J$. 1999;318(7180):372-376. doi:10.1136/bmj.318.7180.372

27. Cunningham MM, Jillings C. Individuals' descriptions of living with fibromyalgia. Clin Nurs Res. 2006;15(4):258-273. doi:10.1177/ 1054773806291853

28. Azoulay L, Ehrmann-Feldman D, Truchon M, Rossignol M. Effects of patient-clinician disagreement in occupational low back pain: A pilot study. Disability Rehab. 2005;27(14):817-823. doi:10.1080/ 09638280400018684

29. Stone J, Warlow C, Sharpe M. The symptom of functional weakness: a controlled study of 107 patients. Brain. 2010;133(5):1537-1551. doi:10.1093/brain/awq068

30. Green A, Payne S, Barnitt R. Illness representations among people with non-epileptic seizures attending a neuropsychiatry clinic: a qualitative study based on the self-regulation model. Seizure. 2004;13(5):331-339. doi:10.1016/j.seizure.2003.09.001

31. Kanaan R, Armstrong D, Wessely S. Limits to truth-telling: neurologists' communication in conversion disorder. Patient Edu Counseling. 2009;77(2):296-301. doi:10.1016/j.pec.2009.05.021

32. Stone J, Carson A, Sharpe M. Functional symptoms and signs in neurology: assessment and diagnosis. J Neurol, Neurosurgery Psychiatry. 2005;76(suppl 1):i2i12. doi:10.1136/jnnp.2004.061655

33. Reuber M, Mitchell AJ, Howlett SJ, Crimlisk HL, Grünewald RA. Functional symptoms in neurology: questions and answers. J Neurol, Neurosurgery Psychiatry. 2005;76(3):307-314. doi:10.1136/jnnp. 2004.048280 


\section{Publish your work in this journal}

Neuropsychiatric Disease and Treatment is an international, peerreviewed journal of clinical therapeutics and pharmacology focusing on concise rapid reporting of clinical or pre-clinical studies on a range of neuropsychiatric and neurological disorders. This journal is indexed on PubMed Central, the 'PsycINFO' database and CAS, and is the official journal of The International Neuropsychiatric Association (INA). The manuscript management system is completely online and includes a very quick and fair peer-review system, which is all easy to use. Visit http://www.dovepress.com/testimonials.php to read real quotes from published authors. 